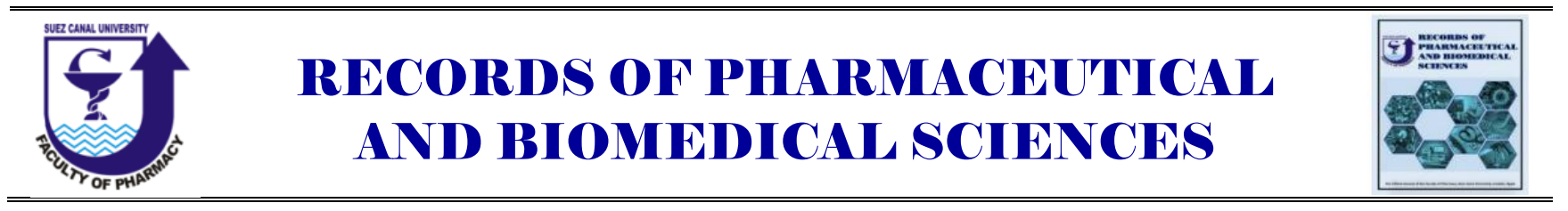

\title{
Incidence of sepsis in adult patients in intensive care units in Ismailia main hospitals
}

\author{
Mohamed Y. Farag a , Marwa M. Azab ${ }^{a^{*}}$, Emad Eldin A. Ibrahim ${ }^{b}$, Eman A. Toraih \\ ALi A. Abdelrahman ${ }^{a}$ \\ ${ }^{a}$ Department of Microbiology and Immunology, Faculty of Pharmacy, , Suez Canal University, Ismailia, \\ Egypt. \\ ${ }^{b}$ Department of Anesthesia and Intensive care, Faculty of Medicine, Suez Canal University, Ismailia, Egypt \\ ${ }^{c}$ Genetics Unit, Faculty of Medicine, Suez Canal University, Ismailia, Egypt
}

Received on: 19.08. 2019

Revised on: 26. 08. 2019

Accepted on: 28. 08. 2019

Correspondence Author:

Tel: +201024299630

E-mail address:

marwaazab2515@yahoo.com.

\begin{abstract}
The Infection is one of the primary causes of human mortality. In the intensive care units a serious complication of infection is sepsis and its complications severe sepsis and septic shock. The incidence of sepsis differs from one place to another place across the world. We aim is to estimate the incidence of sepsis in main hospitals of Ismailia city and to compare this result with results from studies in intensive care units in hospitals in other cities and countries. An observational that has been done in intensive care units of main hospital in Ismailia city. This study showed that cumulative incidence of sepsis to be $5.5 \%$ in a period of seven months which is lower than the incidence of severe sepsis in SOAP study and some other studies.
\end{abstract}

Keywords: Sepsis, incidence, ICU.

\section{Introduction}

Sepsis is identified as a syndrome of physiologic, pathologic and biochemical abnormalities which is triggered by infection, and it results in more than $\$ 20$ billion $(5.2 \%)$ of total hospital costs in United States in 2011 (Torio and Andrews, 2013). Sepsis is a common and a lifethreatening illness, which is considered as a serious public health problem (Keeley et al, 2017). Sepsis is a fatal disease which is a serious lifethreatening illness. A hospitalized sepsis-patient is found to be more likely to die than patients diagnosed with heart attack or stroke (Hall, 2013). The incidence of sepsis varies across the world (Álvaro et al, 2018). In the United States the incidence of severe sepsis has been found to be around 300 cases per 100,000 population, and those who are treated in the intensive care units (ICUs) are found to be about half of that number (Angus et al,2001). In Sweden the incidence of severe sepsis in 2005 was 430 per 100,000 population (Wilhelms et al, 2010). In 1990 the Center for Disease Control and Prevention conducted the first research about epidemiology of sepsis in the US (Centers for Disease Control (CDC), 1990). After about a decade from that, many studies estimated the incidence of sepsis (Wilhelms et al, 2010), (Martin et al, 2003), (Dombrovskiy et al, 2005), (Melamed et al, 2009). 
Angus et al. (Angus et al, 2001) estimated incidence of severe sepsis in seven states in United States, then Martin et al. (Martin et al, 2003) found an increase in the incidence or severe sepsis from 1979 to 2000. After that Dombrovskiy et al. (Dombrovskiy et al, 2005), and Melamed et al. (Melamed et al, 2009) performed similar researches. Other studies which use clinical definitions and ICU observational designs instead of depending on databases have been conducted as well (Vincent et al, 2006), (Brun et al,2012), (Finfer et al,2004), (Padkin et al, 2003). Our aim is to estimate the incidence of sepsis in main hospitals of Ismailia city and to compare this result with results from studies in intensive care units in hospitals in other cities and countries.

\section{Experimental:}

This is an observational that has been done in intensive care units of Suez Canal university hospitals which are the main intensive care units in Ismailia city. All adult patient (more than or equal 18 years) admitted in a period of seven months from 1 December 2017 to 30 June 2018 were screened for presence of sepsis.

\section{Diagnosis}

Patients were screened for the presence of sepsis according to the criteria of The Third International Consensus Definitions for Sepsis and Septic Shock (Sepsis-3) (Singer et al, 2006).

\section{Sepsis clinical criteria}

Patients who have a suspected infection and are likely to have a prolonged stay in ICU or to die in the hospital can be identified with qSOFA at the bedside; i.e. 2 or more of:

- Hypotension: Systolic Blood Pressure less than or equal to $100 \mathrm{mmHg}$

- Altered mental status (Glasgow coma Scale less than 15)

- Tachypnoea: Repiratory Rate greater than or equal to 22

- Organ dysfunction definition is an increase of 2 points or more in the Sequential Organ Failure Assessment (SOFA) score (Singer et al, 2006).

Exclusion criteria: Age $<18$, Pregnancy, Patients with radiation therapy, Patients with chemotherapy

Safety Considerations: This was an observational study. No intervention has been conducted.

\section{Results and Discussion}

490 patients were included in the study population who were admitted to intensive care units in Suez Canal university hospitals in the study period and were all adult with on pregnancy or chemotherapy or radiotherapy treatment. 27 patient developed sepsis. Cumulative Incidence of sepsis equals 5.5\% in a period of seven months.

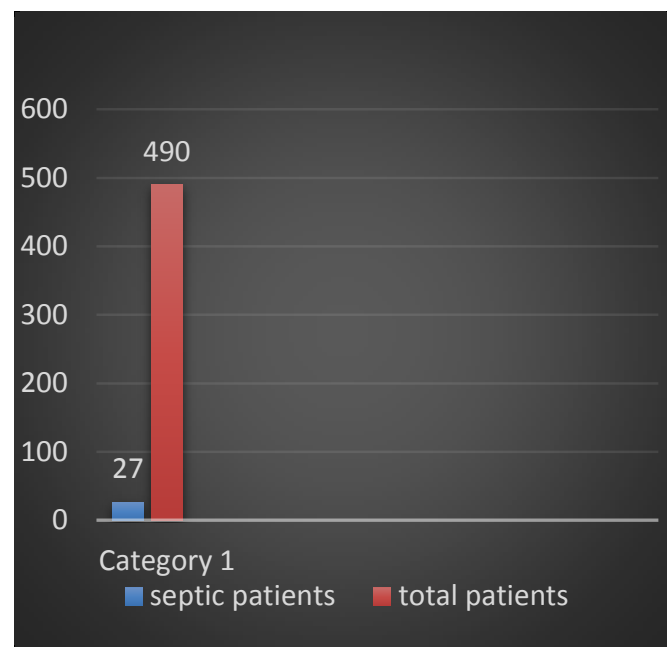

Figure 1:Frequency of sepsis in 7 months

The incidence of sepsis found in this study in Ismailia city is low compared with the measured incidence in other studies which have been made in different countries.

Table 1: Incidence of sepsis in Ismailia city compared with different countries.

\begin{tabular}{|l|l|}
\hline \multicolumn{1}{|c|}{ Location of study } & Incidence \\
\hline 198 European ICUs & $30 \%$ \\
\hline $\begin{array}{l}\text { French study that included 206 } \\
\text { ICUs }\end{array}$ & $14.6 \%$ \\
\hline $\begin{array}{l}\text { 23 ICUs in Australia and New } \\
\text { Zealand }\end{array}$ & $11.8 \%$ \\
\hline $\begin{array}{l}\text { ICUs in the United } \\
\text { Kingdom }\end{array}$ & $27.1 \%$ \\
\hline
\end{tabular}

We found that cumulative incidence of sepsis to be $5.5 \%$ in a period of seven months, while the incidence of severe sepsis in studies in developed world was higher than 5.5\%.In the SOAP study which included 198 European ICUs the average was $30 \%$ (Vincent et al., 2006). 


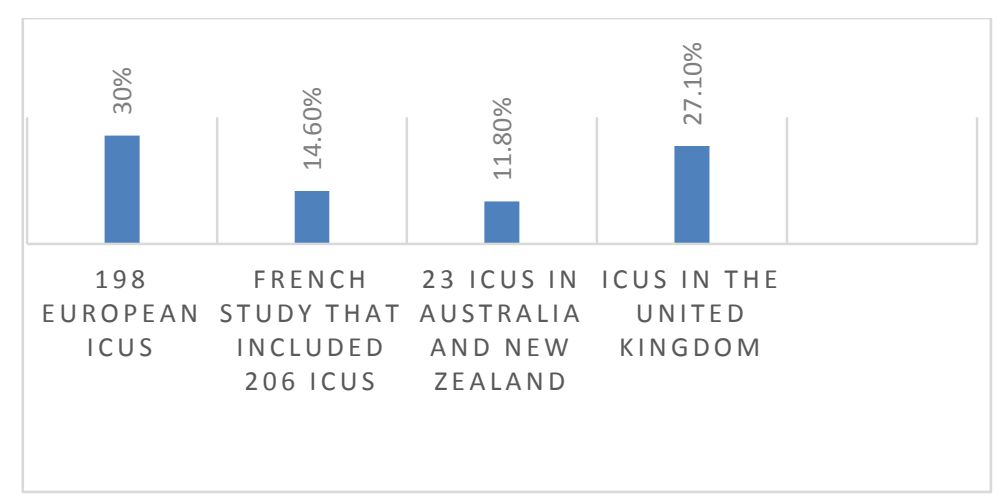

Figure 2: Incidence of severe sepsis in ICUs in different countries (Vincent et al, 2006), (Brun et al, 2004), (Finfer et al, 2004), (Padkin et al, 2003)

In France, a study that included 206 ICUs found that the incidence of severe sepsis is $14.6 \%$ (Brun-Buisson et al., 2004). In a study which was conducted in 23 ICUs in Australia and New Zealand, the incidence of severe sepsis was $11.8 \%$ (Finfer et al., 2004). And in a study in ICUs in United Kingdom during the first $24 \mathrm{~h}$ after ICU admission, the incidence was $27.1 \%$ (Padkin et al., 2004). This result reflects the improvement and development in the healthcare system in Egypt and Ismailia in the last years (Talaat et al., 2006). But, recent study found that incidence of sepsis in adult patients in an ICU can be significantly underestimated (Valentine et al., 2019). This recent Australian study which was published in March 2019 suggested adjustments and conditions to avoid underestimating that should be done before assuming that the calculated incidence is truly reflective of the incidence. Our study was also a small study which has been conducted in Ismailia which is a small governorate in Egypt and included small number of patients compared with those studies in the developed countries, so we recommend that future study to be conducted at a larger scale.

\section{Conclusion}

Cumulative incidence of Sepsis in Suez Canal university hospitals which are the main hospitals in Ismailia is $5.5 \%$ which is lower than the incidence of severe sepsis in SOAP study and some other studies conducted in United Kingdom, France, Australia and New Zealand.

\section{Conflict of Interest}

The authors have no conflict of interest to declare.

\section{References}

Álvaro-Meca A, Jiménez-Sousa MA, Micheloud D, Sánchez-Lopez A, Heredia-Rodríguez , Tamayo E, Resino Sm, 2018. Epidemiological trends of sepsis in the twenty-first century (2000-2013): an analysis of incidence, mortality, and associated costs in Spain. Popul Health Metr. 16(1):4.

Angus DC, Linde-Zwirble WT, Lidicker J, Clermont G, Carcillo J, Pinsky MR ., 2001, Epidemiology of severe sepsis in the United States: analysis of incidence, outcome, and associated costs of care. Crit Care Med, 29(7):1303-1310.

Brun-Buisson C, Meshaka P, Pinton P, et al., 2004. EPISEPSIS: a reappraisal of the epidemiology and outcome of severe sepsis in French intensive care units. Intensive Care Med., 30:580-588.

Centers for Disease Control (CDC), 1990. Increase in National Hospital Discharge Survey rates for septicemia-United States, 1979-1987. MMWR Morb Mortal Wkly Rep., 39:31-34.

Dombrovskiy VY, Martin AA, Sunderram J, et al., 2005. Facing the challenge: decreasing case fatality rates in severe sepsis despite increasing hospitalizations. Crit Care Med., 33:2555-2562.

Finfer S, Bellomo R, Lipman J, et al., 2004. Adultpopulation incidence of severe sepsis in Australian and New Zealand intensive care units. Intensive Care Med., 30:589-596.

Hall MJ, Levant S, DeFrances CJ., 2013. Trends in inpatient hospital deaths: National Hospital Discharge Survey, 2000-2010. NCHS data brief, 118:1-8.

Keeley A, Hine P, Nsutebu E., 2017. The 
recognition and management of sepsis and septic shock: a guide for non-intensivists. Postgrad Med J., 1104:626-634.

Martin GS, Mannino DM, Eaton S, et al., 2003.The epidemiology of sepsis in the United States from 1979 through 2000. N Engl J Med., 348:1546-54.

Melamed A, Sorvillo FJ., 2009., The burden of sepsis-associated mortality in the United States from 1999 to 2005: an analysis of multiple-causeof-death data. Crit Care, 13(1):R28.

Padkin A, Goldfrad C, Brady AR, et al., 2003. Epidemiology of severe sepsis occurring in the first $24 \mathrm{hrs}$ in intensive care units in England, Wales, and Northern Ireland. Crit Care Med., 31:23322338.

Singer M, Deutschman CS, Seymour CW, et al., 2016. The third international consensus definitions for sepsis and septic shock (sepsis3). JAMA, 315:801-810.

Talaat M, Kandeel A, Rasslan O, Hajjeh R, Hallaj
Z, El-Sayed N, et al., 2006. Evolution of infection control in Egypt: achievements and challenges. AmJ Infect Control, 34(4):193-200.

Torio CM, Andrews RM., (2013). National inpatient hospital costs: the most expensive conditions by payer, available from https://www.ncbi.nlm.nih.gov/books/NBK169005/ [accessed 14 March 2019].

Valentine JC, Haeusler G, Worth L, Thursky K., 2019. Sepsis: incidence and mortality are underestimated in Australian intensive care unit administrative data. Med J., 210(4):188-188.

Vincent JL, Sakr Y, Sprung CL, et al., 2006. Sepsis in European intensive care units: results of the SOAP study. Crit Care Med., 34:344-353.

Wilhelms SB, Huss FR, Granath G, Sjöberg F., 2010. Assessment of incidence of severe sepsis in Sweden using different ways of abstracting International Classification of Diseases codes: difficulties with methods and interpretation of results. Crit Care Med., 38(6):1442-1449. 